\title{
Diabetes, heart damage, and angiotensin II. What is the relationship link between them? A minireview
}

\author{
Adriana Pedreanez ${ }^{1}$, Jesus Mosquera ${ }^{2}$, Nelson $\mathrm{Munoz}^{3}$, Jorge Robalino ${ }^{4}$, Diego Tene ${ }^{5}$ \\ ${ }^{1}$ Catedra de Inmunologia, Escuela de Bioanalisis, Facultad de Medicina, Universidad del Zulia, Maracaibo, Venezuela; \\ ${ }^{2}$ Instituto de Investigaciones Clinicas "Dr. Americo Negrette", Facultad de Medicina, Universidad del Zulia, Maracaibo, \\ Venezuela; ${ }^{3}$ Universidad Nacional del Chimborazo, Facultad de Ciencias de la Salud, Riobamba, Ecuador; ${ }^{4}$ Instituto \\ INGINOST, Riobamba, Ecuador; ${ }^{5}$ Hospital General IESS, Riobamba, Ecuador \\ E-mail:apedreanez@gmail.com
}

\begin{abstract}
Cardiovascular complications are the main cause of mortality and morbidity in the diabetic patients, in whom changes in myocardial structure and function have been described. Numerous molecular mechanisms have been proposed that could contribute to the development of a cardiac damage. In this regard, angiotensin II (Ang II), a proinflammatory peptide that constitutes the main effector of the renin-angiotensin system (RAS) has taken a relevant role. The aim of this review was to analyze the role of Ang II in the different biochemical pathways that could be involved in the development of cardiovascular damage during diabetes. We performed an exhaustive review in the main databases, using the following terms: angiotensin II, cardiovascular damage, renin angiotensin system, inflammation, and diabetes mellitus. Classically, the RAS has been defined as a complex system of enzymes, receptors, and peptides that help control the blood pressure and the fluid homeostasis. However, in recent years, this concept has undergone substantial changes. Although this system has been known for decades, recent discoveries in cellular and molecular biology, as well as cardiovascular physiology, have introduced a better understanding of its function and relationship to the development of the diabetic cardiomyopathy.
\end{abstract}

Key words: Angiotensin II, cardiovascular disease, diabetes, renin-angiotensin system

The renin-angiotensin system (RAS) has classically been defined as an endocrine system involved in the regulation of blood pressure, sodium concentration, and extracellular fluid balance (Chappell 2016). However, it is now known that the RAS is locally expressed in several tissues and exerts multiple paracrine and autocrine effects involved in physiology and tissue homeostasis. In fact, RAS plays a key role in the cell proliferation, differentiation, migration, and apoptosis, as well as extracellular matrix (ECM) remodeling (Bader 2010).

RAS has been extensively studied and is present in most vertebrates. Beginning with the discovery of renin more than a century ago (Tigerstedt and Bergman 1898), the RAS has been evolved in an extensive system of bioactive peptides that result from the action of several enzymes on a single precursor, angiotensinogen (AGT) (Dell'Italia 2011). These peptides have specific receptors that produce unique cellular responses in multiple tissues (Dell'Italia 2011).

It has been widely described that alterations in the RAS are involved in multiple diseases, such as atherosclerosis, cardiac hypertrophy, type 1 diabetes, type 2 diabetes, and renal fibrosis (Nehme and Zibara 2017; Nehme et al. 2019). On the other hand, RAS blocking

Corresponding author: Dr. Adriana Pedreanez, Catedra de Inmunologia, Escuela de Bioanalisis, Facultad de Medicina, Universidad del Zulia, P.O. Box 23, Maracaibo 4001-A, Zulia, Venezuela; phone: +58-261-7597247; e-mail: apedreanez@gmail.com. 
agents, such as angiotensin-converting enzyme (ACE) inhibitors and angiotensin II (Ang II) AT1 receptor blockers, have been shown to improve the prognosis of patients with cardiovascular diseases (Crowley et al. 2007).

Ang II is the main effector molecule of RAS. It is involved in the control of blood pressure and electrolyte balance. In addition, as a potent vasoconstrictor, Ang II also exerts proliferative, proinflammatory, and profibrotic activities (Benigni et al. 2010; Forrester et al. 2018). Patients with diabetes are at high risk for cardiovascular diseases (CVD), which is the main cause of morbidity and mortality. These patients have a 2- to 3-fold increased risk of cardiovascular events compared with their nondiabetic counterparts and mortality associated with cardiovascular events is about $80 \%$ in these individuals (Tonelli et al. 2012). The aim of this review is to analyze the role of Ang II in the different molecular pathways that could lead to a cardiovascular pathology during diabetes.

\section{Methods}

A comprehensive search was conducted in the following databases: PubMed, Scopus, and Science Direct. The different sources consulted were reviewed independently by all the authors. The keywords used individually or combined for this search were: angiotensin II, renin-angiotensin system, cardiovascular damage, inflammation, and diabetes mellitus. Observational studies, review articles, and clinical guidelines were also reviewed. In order to evaluate the quality evidence, only original articles were selected.

\section{Overview of the renin-angiotensin system today}

The RAS is a system of hormones, various enzymes, and inactive and active peptides, which together play an important role in the regulation of blood pressure and fluid and electrolyte homeostasis through coordinated effects on the heart, blood vessels, and kidneys (Bader 2010; Chappell 2016).

Ang II is the primary effector hormone of this system that can act either as a systemic hormone or a factor produced locally in tissues. Within the kidney, cells of the juxtaglomerular apparatus synthesize an aspartyl protease called renin (Sequeira Lopez et al. 2004), a very specific enzyme, which acts on AGT synthesized in the liver catalyzing the first step in a biochemical cascade of enzymatic processes. By acting on angiotensinogen, renin gives, it rises to the decapeptide angiotensin I (Ang I), which is subsequently converted to the octapeptide Ang II by the action of angiotensin converting enzyme (ACE) (Hobart et al. 1984). ACE is a glycoprotein with a molecular mass of $18 \mathrm{kDa}$ and two carboxy-terminal active sites, which can also metabolize bradykinin (BK), an active vasodilator and natriuretic substance, to an inactive metabolite (Soubrier et al. 1993; Kuoppala et al. 2000).

Ang II exerts its physiological actions primarily through two distinct receptors: the Ang II type 1 (AT1) and type 2 (AT2). Although Ang II binds with similar affinity to both receptors, most of its functions are mediated by binding to the AT1 receptor (Carey and Padia 2008). Binding of Ang II to the AT1 receptor activates a series of signaling cascades that lead to tissue remodeling, acute vasoconstriction, and water and salt reabsorption. Whereas the binding to the AT2 receptor is thought to have opposite effects, as it has been reported to inhibit and antagonize AT1 receptor-mediated functions through compensatory responses, in particular through nitric oxide release and anti-proliferative properties (Horiuchi et al.2012).

In 2000, angiotensin-converting enzyme type 2 (ACE-2) was reported as first; since then, compensatory RAS pathways have been described (Donoghue et al. 2000; Tipnis et al. 2000). The ACE-2 cleaves Ang I to generate Ang 1-9, which is then converted to the vasodilator peptide Ang 1-7 by the action of ACE or other peptidases. More efficiently, ACE-2 also directly metabolizes Ang II to form Ang 1-7. This heptapeptide has properties opposite to those of Ang II, promoting vasodilation exerting antiproliferative and anti-hypertrophic effects by acting through the Mas receptor (MasR) (Santos et al. 2003). Some reports have also described binding of Ang 1-7 to AT2 receptors (Walters et al. 2005). In addition to the above components of the RAS, Ang II is further metabolized to Ang III by the action of aminopeptidase $\mathrm{A}$ and then converted to Ang IV by the action of aminopeptidase N (Gao et al. 2014). Ang II can also be converted to angiotensin A (Ang A) by the enzyme aspartate decarboxylase derived from mononuclear leukocytes (ADDLM), leading to the formation of Alamandin, which has been shown to bind to the Mas-related G-protein-coupled D receptor (Hrenak et al. 2016). Ang A and Alamandin have antagonistic effects. The former induces vasoconstriction and cell proliferation, whereas the latter triggers opposite effects. Alamandin can be generated from both "harmful" Ang A and "protective" Ang 1-7. This constitutes an additional axis that modulates the regulation of the peripheral and central blood pressure and cardiovascular remodeling in the complex structure of the RAS (Figure 1) (Hrenak et al. 2016). 


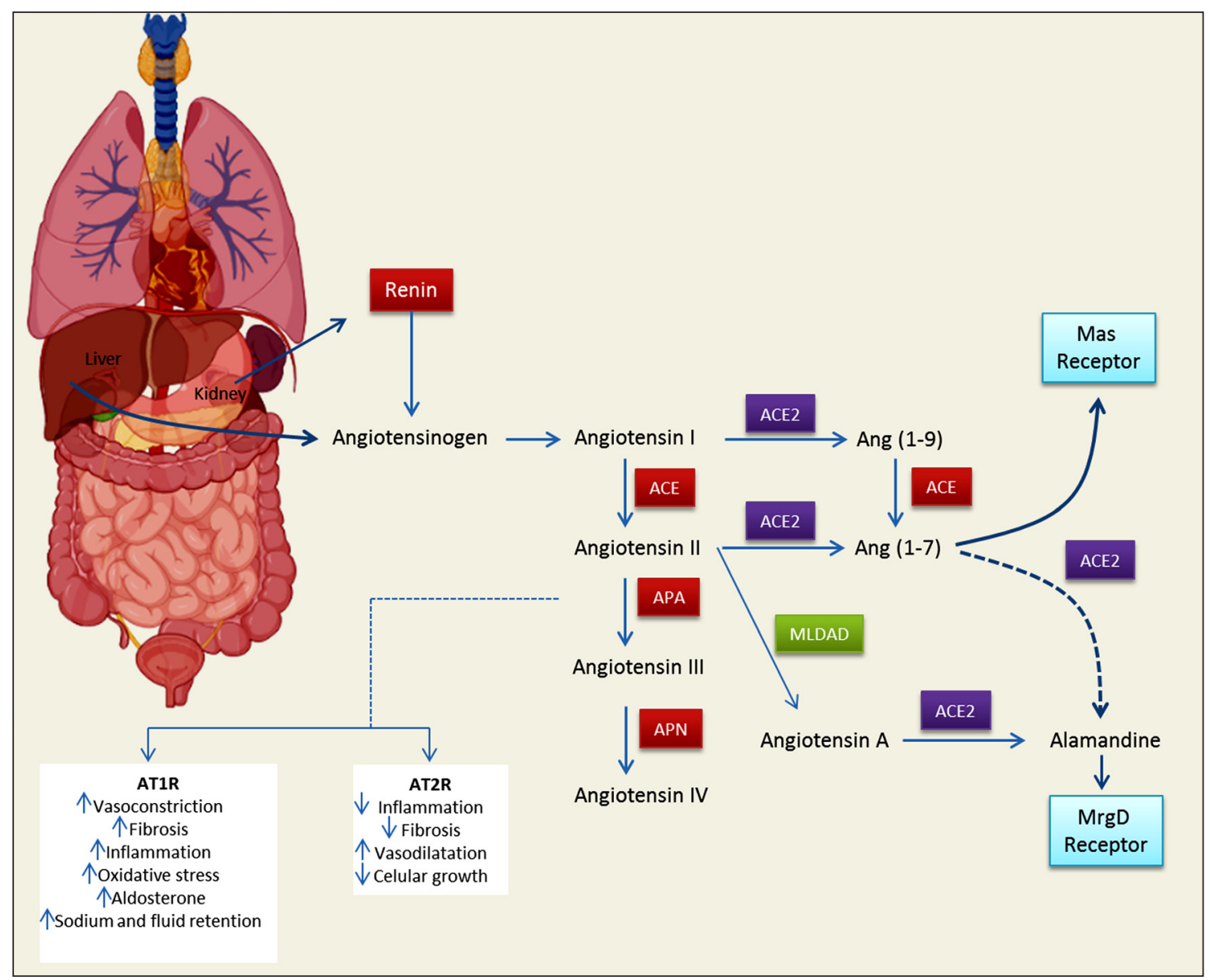

Figure 1. An overview of the renin-angiotensin system. Abbreviations: ACE - angiotensin-converting enzyme; APA aminopeptidase A; APN - aminopeptidase N; ACE-2 - angiotensin-converting enzyme 2; Ang (1-9) - angiotensin 1-9; Ang (1-7) - angiotensin 1-7; MLDAD - mononuclear leukocyte-derived aspartate decarboxylase; MrgD - Mas-related D receptor coupled to G protein; AT1R - AT1 receptor; AT2R - AT2 receptor.

\section{The renin-angiotensin system in cardiac tissue}

In recent years, an abundance of research has been published demonstrating the existence of multiple enzymatic pathways for the generation of different angiotensin peptides that exert their effects in a tissuespecific manner (Ferrario et al. 2014). The concept of local RAS was initially challenged by the fact that renin was considered for a specific RAS limiting enzyme, a key element in the cleavage of GTS into Ang-I. However, in 1971, Ganten and coworkers have described a renin-like enzyme present in dog brain tissue that was independent of renal and plasma renin. This finding marked the beginning of the demonstration of the existence of a tissue RAS. Since then, local angiotensin pathways and their physiological significance have been described in different tissues, including the heart, blood vessels, kidney, brain, adipose tissue, adrenal gland, pancreas, liver, reproductive system, lymphatic tissue, placenta, and eye (Paul et al. 2006; Ferrario et al. 2014).

All major components of the classical RAS, i.e., renin, AGT, ACE, AT1, and AT2 receptors, are expressed in the heart, although there is a lack of consensus on the source of renin (Krop and Danser 2008). However, it is known that regardless of this fact, most of cardiac Ang II is synthesized in situ (van Kats et al. 1998). The difference in circulating and cardiac Ang II levels is particularly prominent in diabetes. Hyperglycemia increases tissue Ang II even in the heart, which induces oxidative stress, endothelial damage, vasoconstriction, thrombosis, inflammation, and vascular remodeling (Giacchetti et al. 2005; Singh et al. 2008a, b).

Several studies have demonstrated uptake and activation of prorenin by cardiomyocytes resulting 
in an increased intracellular Ang II levels, suggesting that intracellular Ang II synthesis may occur after sequestration of prorenin and AGT by these cells (van Kesteren et al. 1997; Peters et al. 2002). On the other hand, Singh and coworkers (2007), have demonstrated Ang II synthesis in neonatal rat ventricular myocytes using specific enzyme inhibitors and have concluded that renin and ACE are involved in Ang II synthesis, while Ang II generation induced by high glucose concentration involved renin and chymase. Fibroblasts constitute the second major cell type in the heart that play an important role in the cardiac remodeling in various pathological conditions. Fibroblasts have been described to contain a full RAS and respond to stimulation by producing Ang II that induces extracellular matrix production (Sanghi et al. 2005). The close proximity and interaction of cardiac myocytes and fibroblasts make cardiac fibroblasts of critical importance, when considering the paracrine or autocrine effects of Ang II in the heart. Previous experiments have demonstrated that cardiac fibroblasts stimulated with high doses of glucose or isoproterenol produced Ang II in an intraand extracellular manner dependent on the action of renin and ACE, but not chymases (Singh et al. 2008a, b). In this context, it has been described that in addition to renin, other enzymes such as cathepsin
D (CTSD), cathepsin G (CTSG), and tonin have a capacity to degrade TFA and generate Ang I (Wu et al. 2011). These constitute additional pathways for the generation of Ang II that would escape to known blocking mechanisms.

One of the most important contributions leading to the understanding of the local RAS is the discovery of angiotensin peptide (1-12), which may serve as an alternative precursor for Ang II production. Ang 1-12 was first described in 2006 and induces aortic constriction ex vivo and elevates blood pressure in rats (Nagata et al. 2006). This substrate in the presence of mast cell protease (chymase) is directly converted to Ang II in humans (Ahmad et al. 2011; Ferrario et al. 2016). Mast cells normally exist in an intact form within the myocardium and can be activated by releasing enzymes, such as chymase, in response to acute stress, such as ischemia/reperfusion and oxidative stress (Zheng et al. 2014). These alternative pathways may explain in part the dual function of RAS, not only as a circulating hormone system, but also as a tissue-specific regulatory system that serves autocrine, paracrine, and even intracrine functions.

The most significant observation regarding cardiac RAS is the glucose-induced intracellular synthesis and complete retention of Ang II in cardiomyocytes. These observations are important not only for

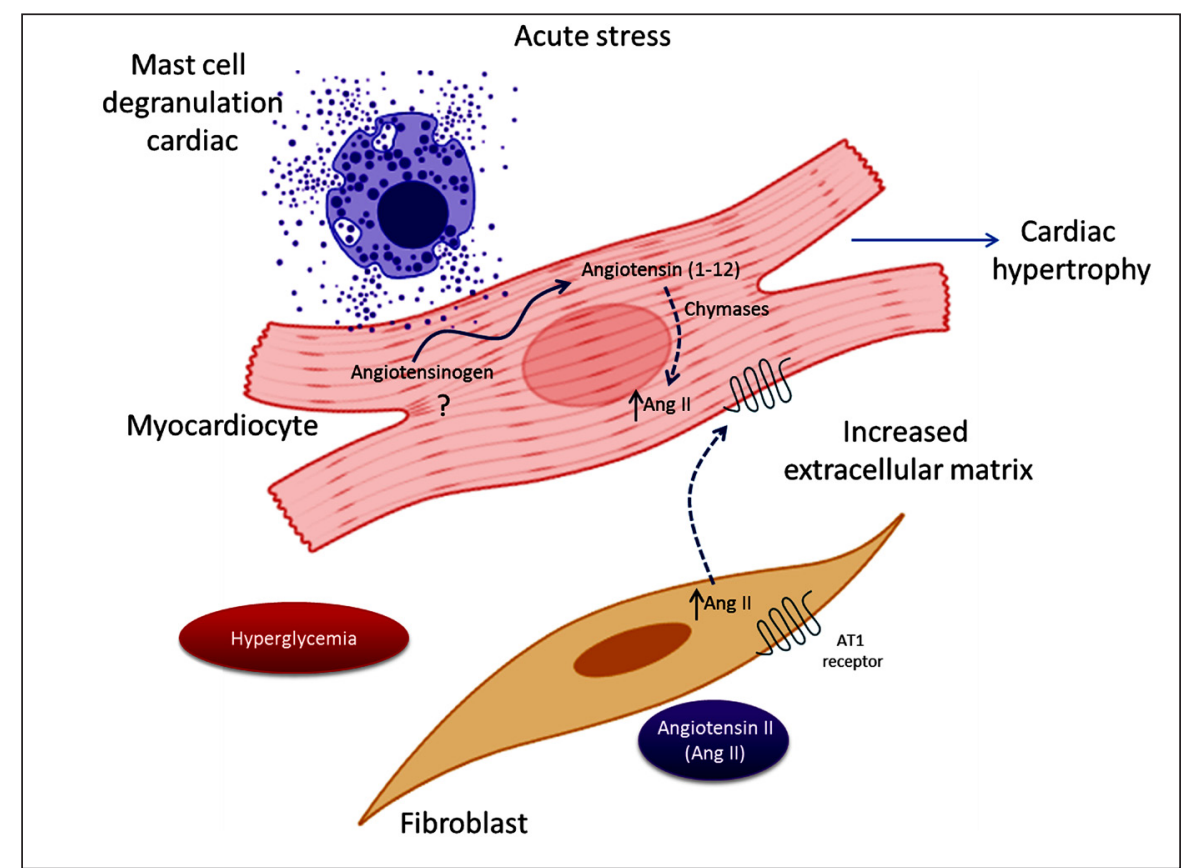

Figure 2. A representative scheme depicting the paracrine communication network between the cardiac fibroblasts and myocytes, chymase-dependent angiotensin II (Ang II) production, and the effect of hyperglycemia on Ang II production in these cells. 
understanding the RAS in diabetes, but also for the clinical management of diabetic cardiomyopathy (Singh et al. 2007, 2008a, b). The key step in the effector mechanisms of the RAS is the binding of Ang II to AT1 receptors. This initiates a signal transduction cascade that results in collagen synthesis by cardiac fibroblasts, causing fibrosis and myocyte hypertrophy, which underlie the development of cardiac hypertrophy (Figure 2) (Krenning et al. 2010).

\section{Angiotensin II and cardiovascular damage in diabetes}

Cardiovascular disease remains the leading cause of morbidity and mortality in type land 2 diabetes (Livingstone et al. 2012; Paneni et al. 2013; Miller et al. 2019). Beyond the inherent increase in mortality in diabetic subjects, when diabetes is combined with manifestations of cardiovascular disease, i.e., disorders of the heart and blood vessels, such as myocardial infarction or stroke, the mortality rate nearly doubles, leading to an estimated reduction in life expectancy by approximately 12 years (Pennells et al. 2019). Multiple evidences support the widely accepted fact that RAS activation represents a mechanism linking diabetes and cardiovascular complications (Weinsaft 2000). In addition to the systemic RAS activation, the induction of this pathway also occurs locally in the heart during diabetes (Bugger and Abel 2014). ACE inhibitors have been shown to reduce the risk of heart failure in patients with diabetes or established cardiovascular disease (Ghali et al. 2007; Aguilar et al. 2010). RAS activation in diabetes may also contribute to inflammation (Candido et al. 2004), cardiac fibrosis, and oxidative stress (Fiordaliso et al. 2006), which promotes cardiac remodeling that could be reversed or prevented by blocking it (Fiordaliso et al. 2006; Matsusaka et al. 2006).

A prominent feature of diabetic myocardium is cardiac hypertrophy (increased ventricular mass and wall thickness), which is accompanied by a compromised systolic and diastolic function (Lee et al. 1997; Singh et al. 2007, 2008a, b; Devereux et al. 2000). In this regard, several studies have demonstrated an increase in the mouse hearts connective tissue with streptozotocin (STZ)-induced diabetes, which can be attenuated by treatment with aldosterone antagonists (Westermann et al. 2007; Kumar et al. 2008). In addition, increased cardiac Ang II receptor density and synthesis, an increased superoxide anion production and apoptosis have been demonstrated, which can be at least partially inhibited by treatment with angiotensin receptor blockers or ACE inhibitors (Brown et al. 1997; Singh et al. 2008a, b). This is why these drugs remain the first-line therapy for the prevention of CVD in patients with diabetes (ESH/ESC 2013). Chronic hyperglycemia and insulin resistance play an important role in the onset of the diabetes vascular complications and involve a number of mechanisms including increased formation of advanced glycation end products (AGEs) and activation of the receptor for advanced glycation end products (RAGE) with a consequent induction of oxidative stress and inflammation (Brownlee 2005).

AGEs represent a heterogeneous group of compounds formed by nonenzymatic glycation and glycoxidation of proteins, nucleic acids, and lipids with reducing sugars (Thorpe and Baynes 2003). These compounds interact with 2 main types of receptors: scavenger receptors, which remove and degrade AGEs and receptors for advanced glycation end products (RAGE), the latter, which triggers a specific cell signaling responses after AGE binding. RAGE is a member of the immunoglobulin superfamily and binds to many ligands. In addition to AGEs. RAGE, it can also bind high-mobility group protein B1, S100 calcium-binding proteins (including calgranulin), $\beta$-amyloid protein, and amphotericin (Mosquera 2010). The AGE-RAGE axis sends biochemical signals through the transcription factor NF- $\kappa \mathrm{B}$, using pathways such as mitogen-activated protein kinases (MAPK; ERK1 / 2, p38MAPK) and NADPH oxidase (nicotinamide adenine dinucleotide phosphate)(Nox) inducing the expression of adhesion molecule 1, E-selectin, vascular endothelial growth factor, and several proinflammatory cytokines (IL-1 $\beta$, IL-6, TNF-a) (Manigrasso et al. 2014).

There is evidence for the involvement of RAGE in Ang II-induced ventricular hypertrophy (Manigrasso et al. 2014). It has been reported that inhibition of RAS and RAGE signaling almost completely inhibits the development of atherosclerosis associated with experimental diabetes (Watson et al. 2014). Recently, our laboratory has reported an increase in the myocardial expression of RAGE and ED1(monocytes/ macrophages) in heart biopsies and increased plasma Endothelin-1 concentration in Sprague Dawley rats, using a model of experimental diabetes induced with streptozotocin. These parameters decreased after treatment with Enalapril and Losartan, suggesting a possible involvement of Ang II as a mediator of the inflammatory process through activation of RAGE and Endothelin-1 production (Munoz et al. 2020). Evidence suggests that diabetes is accompanied 
by a proinflammatory state, since an increase in factors that regulate and/or biomark inflammatory responses, such as high-sensitivity C-reactive protein (hsCRP), toll-like receptors (TLR), oxidative stress, increased NF-kB expression, increased AGEs, and increased its main receptor on the cell surface (RAGE) have been described (Hayaishi-Okano et al. 2002; Dasu et al. 2010; Daffu et al. 2013; Lopez-Diez et al. 2016).

It has been suggested that the initial trigger, by which the high glucose concentrations alter the vascular function is the imbalance between the nitric oxide (NO) bioavailability and the reactive oxygen species (ROS) accumulation, which results in an oxidative stress leading to endothelial dysfunction (Creager et al. 2003). Oxidative stress is defined as a state of imbalance, in which the production of ROS, including superoxide anion $\left(\mathrm{O}^{2-}\right)$, hydrogen peroxide $\left(\mathrm{H}_{2} \mathrm{O}_{2}\right)$, and hydroxyl radicals $(\mathrm{OH})$, exceeds antioxidant defenses (Creager et al. 2003). There are several enzyme systems that contribute to the formation of ROS, including NADPH oxidase, xanthine oxidase, and mitochondrial electron leakage from the electron transport chain. ROS are normally generated as a natural by-product of oxygen metabolism playing an important role in the cell signaling. However, ROS levels can be increased dramatically under conditions of oxidative stress, such as heart failure, ischemia/reperfusion, and aging (Vignais 2002). NADPH oxidase is a multiprotein enzyme complex of five subunits distributed in the cytoplasm, cytoplasmic membranes, and phagocytic vesicles. The NADPH oxidase complex is widely distributed in immune cells as well as endothelial cells, vascular smooth muscle cells, and cardiac myocytes (Xiao et al. 2002). ROS generated by NADPH oxidase were initially recognized as a major source of ROS from the vasculature and later also from the cardiac ROS (Xiao et al. 2002). Previous studies have shown that Ang II can duplicate the production of vascular ROS in vivo in an NADPHdependent manner (Rajagopalan et al. 1996; Vignais 2002). Although the detailed molecular mechanisms for Ang II signaling in NADPH oxidase are still under investigation, a number of possible mediators for NADPH oxidase activation have been hypothesized. Ang II may activate the PLA 2 , PLD, and PKC phosphorylation pathways by binding to AT1 receptors and subsequently activate a cytosolic oxidase subunit the p47 phox, which may migrate to the plasma membrane and participate in the oxidation process (Hitomi et al. 2007).

Ang II is a peptide with proinflammatory properties, capable of inducing the synthesis of

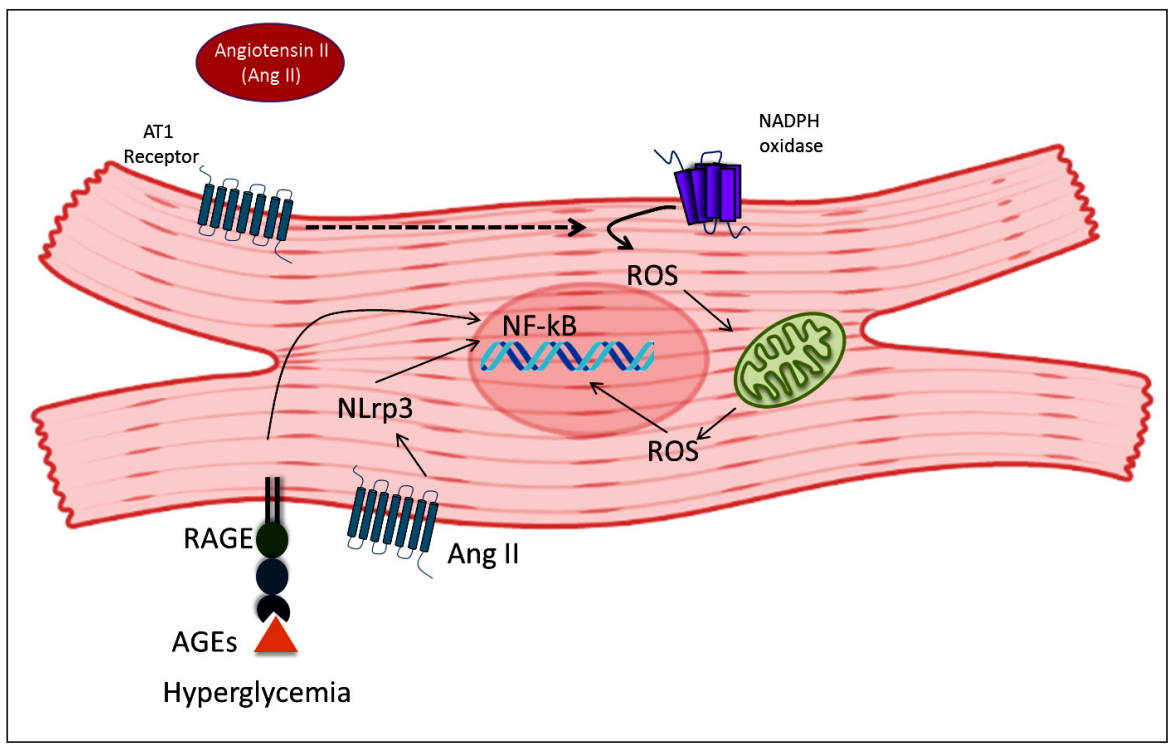

Figure 3. Schematic picture depicting the relationship of angiotensin II (Ang II) with the main biochemical pathways of the cardiovascular damage induction during diabetes. Ang II can induce production of reactive oxygen species (ROS) by promoting the activation of NADPH oxidase, which can generate mitochondrial damage and further ROS production. Additionally, Ang II can activate NF-kB and NLrp3 inflammasome promoting an inflammatory state. It can also induce the RAGE receptor expression, which when activated by advanced glycation end products (AGEs), generates activation of NF-kB and potentiates the inflammatory response. 
cytokines, chemokines, and growth factors, leading to lesions in different organs. These proinflammatory effects are generated by binding to AT1 receptors, which results in the activation of NF-kB either directly or indirectly by stimulating other pathways such as the generation of ROS. This transcription factor was first described in the 1980s (Singh et al. 1986), and is one of the most important transcription factors that plays a critical role in the regulation of innate immunity, inflammatory responses, cell growth, and apoptosis.

$\mathrm{NF}-\kappa \mathrm{B}$ is widely expressed in different mammalian tissues, including humans, and can be activated by a variety of stimuli. Proinflammatory cytokine and chemokine families, including tumor necrosis factor a (TNF- $\alpha$ ), IL-1 and IL-6, microbial lipopolysaccharide (LPS), and ROS, are the most commonly described factors that induce $N F-\kappa B$ activation (Singh et al. 1986; Gilmore 2006). The ability of Ang II to activate NF- $\kappa \mathrm{B}$ has also been demonstrated suggesting its role as an intracellular mediator. Ang II is known to induce target organ damage in cardiovascular, hypertensive, and renal diseases through activation of a number of proinflammatory cytokines, chemokines, and growth factors (Kranzhofer et al. 1999; Ruiz-Ortega et al. 2000).

The proliferative and growth-promoting effects of Ang II may be mediated, in part, by an activation of NF- $\kappa \mathrm{B}$ signaling. Conversely, the beneficial clinical effects of ACE inhibitors and AT1 receptor blockers may also be due, in part, to their effects on inhibition of NF- $\mathrm{kB}$ signaling (Costa et al. 2006; Wu et al. 2006). The proinflammatory activity of Ang II has also been linked to NLrp3 inflammasome activation. The inflammasomes are high-molecular-weight cytosolic complexes that mediate caspase activation and induce inflammation (Abderrazak et al. 2015). The NLrp3 inflammasome is activated by forming an NLrp3 complex consisting of a sensor portion that subsequently oligomerizes and then recruits an apoptosisassociated protein containing a caspase recruitment domain (ASC), which processes pro-caspase-1 to active caspase-1. Activated caspase- 1 facilitates the conversion of pro-interleukin IL-1 $\beta$ to its mature form IL-1 $\beta$ and thereby triggers an inflammatory response (Kang et al. 2014). In this context, it has been recently demonstrated murine Ang II infusioninduced hypertension a model that treatment with EMD638683 (a selective inhibitor of NLrp3 inflammasome activation) has been successful in inhibiting cardiac fibrosis, with a significant reduction in inflammation (Gan et al. 2018). Additionally, the RAGE receptor has been shown to induce cardiac hypertrophy through activation of the PKCs-ERK1/2 and NF- $\kappa \mathrm{B}-\mathrm{NLrp3}-\mathrm{IL}-1 \beta$ signaling pathways, suggesting that the RAGE- NLrp3 axis may be an important mediator of Ang II-induced cardiomyocyte hypertrophy (Figure 3) (Lim et al. 2018).

\section{Conclusion}

Ang II is a proinflammatory peptide that plays a key role in the development and progression of the myocardial dysfunction and the cardiovascular diseases during diabetes. Ang II involvement includes its relationship with the AGEs/RAGE axis, redox imbalance, activation of the transcription factor NF-kB, and the NLrp3 inflammasome. All these biochemical mechanisms appear to interrelate in a complex and intricate biochemical pathways that have, as a common effector at some point, the involvement of Ang II.

\section{References}

Abderrazak A, Syrovets T, Couchie D, El Hadri K, Friguet B, Simmet T, Rouis M. NLRP3 inflammasome: from a danger signal sensor to a regulatory node of oxidative stress and inflammatory diseases. Redox Biol 4, 296-307, 2015.

Aguilar D, Deswal A, Ramasubbu K, Mann DL, Bozkurt B. Comparison of patients with heart failure and preserved left ventricular ejection fraction among those with versus without diabetes mellitus. Am J Cardiol 105, 373$377,2010$.

Ahmad S, Simmons T, Varagic J, Moniwa N, Chappell MC, Ferrario CM. Chymase-dependent generation of angiotensin II from angiotensin-(1-12) in human atrial tissue. PLoS One 6, e28501, 2011.

Bader M. Tissue renin-angiotensin-aldosterone systems: Targets for pharmacological therapy. Annu Rev Pharmacol Toxicol 50, 439-465, 2010.

Benigni A, Cassis P, Remuzzi G. Angiotensin II revisitado: nuevos roles en inflamacion, inmunologia y envejecimiento. EMBO Mol Med 2, 247-257, 2010.

Brown L, Wall D, Marchant C, Sernia C. Tissue-specific changes in angiotensin II receptors in streptozotocin-diabetic rats. J Endocrinol 154, 355-362, 1997. 
Brownlee M. The pathobiology of diabetic complications: a unifying mechanism. Diabetes 54, 1615-1625, 2005.

Bugger H, Abel ED. Molecular mechanisms of diabetic cardiomyopathy. Diabetologia 57, 660-671, 2014.

Candido R, Allen TJ, Lassila M, Cao Z, Thallas V, Cooper ME, Jandeleit-Dahm KA. Irbesartan but not amlodipine suppresses diabetes-associated atherosclerosis. Circulation 109, 1536-1542, 2004.

Carey RM, Padia SH. Angiotensin AT2 receptors: control of renal sodium excretion and blood pressure. Trends Endocrinol Metab 19, 84-87, 2008.

Chappell MC. Biochemical evaluation of the renin-angiotensin system: the good, bad, and absolute? Am J Physiol Heart Circ Physiol 310, H137-H152, 2016.

Costa JC, Costa RS, Silva CG, Coimbra TM. Enalapril reduces the expression of nuclear factor-kappaB and c-Jun N-terminal kinase in the renal cortices of five-sixths-nephrectomized rats. Am J Nephrol 26, 281-286, 2006.

Creager MA, Luscher TF, Cosentino F, Beckman JA. Diabetes and vascular disease: pathophysiology, clinical consequences, and medical therapy: Part I. Circulation 108, 1527-1532, 2003.

Crowley SD, Gurley SB, Coffman TM. AT(1) receptors and control of blood pressure: the kidney and more. Trends Cardiovasc Med 17, 30-34, 2007.

Daffu G, del Pozo CH, O’Shea KM, Ananthakrishnan R, Ramasamy R, Schmidt AM. Radical roles for RAGE in the pathogenesis of oxidative stress in cardiovascular diseases and beyond. Int J Mol Sci 14,19891-19910, 2013.

Dasu MR, Devaraj S, Park S, Jialal I. Increased toll-like receptor (TLR) activation and TLR ligands in recently diagnosed type 2 diabetic subjects. Diabetes Care 33, 861-868, 2010.

Dell'Italia LJ. Translational success stories: angiotensin receptor 1 antagonists in heart failure. Circ Res 109, 437-452, 2011.

Devereux RB, Roman MJ, Paranicas M, O’Grady MJ, Lee ET, Welty TK, Fabsitz RR, Robbins D, Rhoades ER, Howard BV. Impact of diabetes on cardiac structure and function: the strong heart study. Circulation 101, 2271-2276, 2000.

Donoghue M, Hsieh F, Baronas E, Godbout K, Gosselin M, Stagliano N, Donovan M, Woolf B, Robison K, Jeyaseelan R, Breitbart RE, Acton S. A novel angiotensin-converting enzyme-related carboxypeptidase (ACE2) converts angiotensin I to angiotensin 1-9. Circ Res 87, E1-E9, 2000.

ESH/ESC Task Force for the Management of Arterial Hypertension. 2013 Practice guidelines for the management of arterial hypertension of the European Society of Hypertension (ESH) and the European Society of Cardiology (ESC): ESH/ESC Task Force for the Management of Arterial Hypertension. J Hypertens 31, 1925-1938, 2013.

Ferrario CM, Ahmad S, Nagata S, Simington SW, Varagic J, Kon N, Dell'italia LJ. An evolving story of angiotensinII-forming pathways in rodents and humans. Clin Sci (Lond) 126, 461-469, 2014.

Ferrario CM, VonCannon J, Jiao Y, Ahmad S, Bader M, Dell’Italia LJ, Groban L, Varagic J. Cardiac angiotensin-(1-12) expression and systemic hypertension in rats expressing the human angiotensinogen gene. Am J Physiol Heart Circ Physiol 310, H995-H1002, 2016.

Fiordaliso F, Cuccovillo I, Bianchi R, Bai A, Doni M, Salio M, De Angelis N, Ghezzi P, Latini R, Masson S. Cardiovascular oxidative stress is reduced by an ACE inhibitor in a rat model of streptozotocin-induced diabetes. Life Sci 79, 121-129, 2006.

Forrester SJ, Booz GW, Sigmund CD, Coffman TM, Kawai T, Rizzo V, Scalia R, Eguchi S. Angiotensin II signal transduction: An update on mechanisms of physiology and pathophysiology. Physiol Rev 98, 1627-1738, 2018.

Gan W, Ren J, Li T, Lv S, Li C, Liu Z, Yang M. The SGK1 inhibitor EMD638683, prevents Angiotensin II-induced cardiac inflammation and fibrosis by blocking NLRP3 inflammasome activation. Biochim Biophys Acta Mol Basis Dis 1864, 1-10, 2018.

Ganten D, Minnich JL, Granger P, Hayduk K, Brecht HM, Barbeau A, Boucher R, Genest J. Angiotensin-forming enzyme in brain tissue. Science 173, 64-65, 1971.

Gao J, Marc Y, Iturrioz X, Leroux V, Balavoine F, Llorens-Cortes C. A new strategy for treating hypertension by blocking the activity of the brain renin-angiotensin system with aminopeptidase A inhibitors. Clin Sci (Lond) 127, 135-148, 2014.

Ghali JK, Boehmer J, Feldman AM, Saxon LA, Demarco T, Carson P, Yong P, Galle EG, Leigh J, Ecklund FL, Bristow MR. Influence of diabetes on cardiac resynchronization therapy with or without defibrillator in patients with advanced heart failure. J Card Fail 13, 769-773, 2007.

Giacchetti G, Sechi LA, Rilli S, Carey RM. The renin-angiotensin-aldosterone system, glucose metabolism and diabetes. Trends Endocrinol Metab 16, 120-126, 2005.

Gilmore TD. Introduction to NF-kappaB: players, pathways, perspectives. Oncogene 25, 6680-6684, 2006. 
Hayaishi-Okano R, Yamasaki Y, Katakami N, Ohtoshi K, Gorogawa S, Kuroda A, Matsuhisa M, Kosugi K, Nishikawa N, Kajimoto Y, Hori M. Elevated C-reactive protein associates with early-stage carotid atherosclerosis in young subjects with type 1 diabetes. Diabetes Care 25, 1432-1438, 2002.

Hitomi H, Kiyomoto H, Nishiyama A. Angiotensin II and oxidative stress. Curr Opin Cardiol 22, 311-315, 2007.

Hobart PM, Fogliano M, O'Connor BA, Schaefer IM, Chirgwin JM. Human renin gene: structure and sequence analysis. Proc Natl Acad Sci U.S.A. 81, 5026-5030, 1984.

Horiuchi M, Iwanami J, Mogi M. Regulation of angiotensin II receptors beyond the classical pathway. Clin Sci (Lond) 123, 193-203, 2012.

Hrenak J, Paulis L, Simko F. Angiotensin A/Alamandine/MrgD Axis: Another clue to understanding cardiovascular pathophysiology. Int J Mol Sci, 17, 1098, 2016.

Kang TB, Yang SH, Toth B, Kovalenko A, Wallach D. Activation of the NLRP3 inflammasome by proteins that signal for necroptosis. Methods Enzymol 545, 67-81, 2014.

Kranzhofer R, Browatzki M, Schmidt J, Kubler W. Angiotensin II activates the proinflammatory transcription factor nuclear factor-kappaB in human monocytes. Biochem Biophys Res Commun 257, 826-828, 1999.

Krenning G, Zeisberg EM, Kalluri R. The origin of fibroblasts and mechanism of cardiac fibrosis. J Cell Physiol 225, 631-637, 2010.

Krop M, Danser AH. Circulating versus tissue renin-angiotensin system: on the origin of (pro)renin. Curr Hypertens Rep 10, 112-118, 2008.

Kumar R, Singh VP, Baker KM. The intracellular renin-angiotensin system: implications in cardiovascular remodeling. Curr Opin Nephrol Hypertens 17,168-173, 2008.

Kuoppala A, Lindstedt KA, Saarinen J, Kovanen PT, Kokkonen JO. Inactivation of bradykinin by angiotensin-converting enzyme and by carboxypeptidase N in human plasma. Am J Physiol Heart Circ Physiol 278, H1069H1074, 2000.

Lee M, Gardin JM, Lynch JC, Smith VE, Tracy RP, Savage PJ, Szklo M, Ward BJ. Diabetes mellitus and echocardiographic left ventricular function in free-living elderly men and women: The Cardiovascular Health Study. Am Heart J 133, 36-43, 1997.

Lim S, Lee ME, Jeong J, Lee J, Cho S, Seo M, Park S. sRAGE attenuates angiotensin II-induced cardiomyocyte hypertrophy by inhibiting RAGE-NFkB-NLRP3 activation. Inflamm Res 67, 691-701, 2018.

Livingstone SJ, Looker HC, Hothersall EJ, Wild SH, Lindsay RS, Chalmers J, Cleland S, Leese GP, McKnight J, Morris AD, Pearson DW, Peden NR, Petrie JR, Philip S, Sattar N, Sullivan F, Colhoun HM. Risk of cardiovascular disease and total mortality in adults with type 1 diabetes: Scottish registry linkage study. PLoS Med 9, e1001321, 2012.

Lopez-Diez R, Shekhtman A, Ramasamy R, Schmidt AM. Cellular mechanisms and consequences of glycation in atherosclerosis and obesity. Biochim Biophys Acta 1862, 2244-2252, 2016.

Manigrasso MB, Juranek J, Ramasamy R, Schmidt AM. Unlocking the biology of RAGE in diabetic microvascular complications. Trends Endocrinol Metab 25, 15-22, 2014.

Matsusaka H, Kinugawa S, Ide T, Matsushima S, Shiomi T, Kubota T, Sunagawa K, Tsutsui H. Angiotensin II type 1 receptor blocker attenuates exacerbated left ventricular remodeling and failure in diabetes-associated myocardial infarction. J Cardiovasc Pharmacol 48, 95-102, 2006.

Miller RG, Costacou T, Orchard TJ. Risk Factor Modeling for Cardiovascular Disease in Type 1 Diabetes in the Pittsburgh Epidemiology of Diabetes Complications (EDC) Study: A Comparison With the Diabetes Control and Complications Trial/Epidemiology of Diabetes Interventions and Complications Study (DCCT/EDIC). Diabetes 68, 409-419, 2019.

Mosquera J. Papel del receptor para compuestos de glicosilacion avanzada (RAGE) en la inflamacion. Invest Clin 51, 257-268, 2010.

Munoz N, Pedreanez A, Mosquera J. Angiotensin II induces increased myocardial expression of receptor for advanced glycation end products, monocyte/macrophage infiltration and circulating endothelin-1 in rats with experimental diabetes. Can J Diabetes 44, 651-656, 2020.

Nagata S, Kato J, Sasaki K, Minamino N, Eto T, Kitamura K. Isolation and identification of proangiotensin-12, a possible component of the renin-angiotensin system. Biochem Biophys Res Commun 350, 1026-1031, 2006.

Nehme A, Zibara K. Efficiency and specificity of RAAS inhibitors in cardiovascular diseases: how to achieve better end-organ protection? Hypertens Res 40, 903-909, 2017.

Nehme A, Zouein FA, Zayeri ZD, Zibara K. An update on the tissue renin angiotensin system and its role in physiology and pathology. J Cardiovasc Dev Dis 6, 14, 2019. 
Paneni F, Beckman JA, Creager MA, Cosentino F. Diabetes and vascular disease: pathophysiology, clinical consequences, and medical therapy: part I. Eur Heart J 34, 2436-2443, 2013.

Paul M, Poyan Mehr A, Kreutz R. Physiology of local renin-angiotensin systems. Physiol Rev 86, 747-803, 2006.

Pennells L, Kaptoge S, Wood A, Sweeting M, Zhao X, White I, et al. Equalization of four cardiovascular risk algorithms after systematic recalibration: individual-participant meta-analysis of 86 prospective studies. Eur Heart J 40, 621-631, 2019.

Peters J, Farrenkopf R, Clausmeyer S, Zimmer J, Kantachuvesiri S, Sharp MG, Mullins JJ. Functional significance of prorenin internalization in the rat heart. Circ Res 90, 1135-1141, 2002.

Rajagopalan S, Kurz S, Munzel T, Tarpey M, Freeman BA, Griendling KK, Harrison DG. Angiotensin II-mediated hypertension in the rat increases vascular superoxide production via membrane NADH/NADPH oxidase activation. Contribution to alterations of vasomotor tone. J Clin Invest 97, 1916-1923, 1996.

Ruiz-Ortega M, Lorenzo O, Ruperez M, Konig S, Wittig B, Egido J. Angiotensin II activates nuclear transcription factor kappaB through AT(1) and AT(2) in vascular smooth muscle cells: molecular mechanisms. Circ Res 86, 1266-1272, 2000.

Sanghi S, Kumar R, Smith M, Baker KM, Dostal DE. Activation of protein kinase A by atrial natriuretic peptide in neonatal rat cardiac fibroblasts: role in regulation of the local renin-angiotensin system. Regul Pept 132, 1-8, 2005.

Santos RA, Simoes e Silva AC, Maric C, Silva DM, Machado RP, de Buhr I, Heringer-Walther S, Pinheiro SV, Lopes MT, Bader M, Mendes EP, Lemos VS, Campagnole-Santos MJ, Schultheiss HP, Speth R, Walther T. Angiotensin-(1-7) is an endogenous ligand for the G protein-coupled receptor Mas. Proc Natl Acad Sci U S A 100, 8258-8263, 2003.

Sequeira Lopez ML, Pentz ES, Nomasa T, Smithies O, Gomez RA. Renin cells are precursors for multiple cell types that switch to the renin phenotype when homeostasis is threatened. Dev Cell 6, 719-728, 2004.

Singh H, Sen R, Baltimore D, Sharp PA. A nuclear factor that binds to a conserved sequence motif in transcriptional control elements of immunoglobulin genes. Nature 319, 154-158, 1986.

Singh VP, Le B, Bhat VB, Baker KM, Kumar R. High-glucose-induced regulation of intracellular ANG II synthesis and nuclear redistribution in cardiac myocytes. Am J Physiol Heart Circ Physiol 293, H939-H948, 2007.

Singh VP, Baker KM, Kumar R. Activation of the intracellular renin-angiotensin system in cardiac fibroblasts by high glucose: role in extracellular matrix production. Am J Physiol Heart Circ Physiol 294, H1675-H1684, 2008a.

Singh VP, Le B, Khode R, Baker KM, Kumar R. Intracellular angiotensin II production in diabetic rats is correlated with cardiomyocyte apoptosis, oxidative stress, and cardiac fibrosis. Diabetes 57, 3297-3306, 2008 b.

Soubrier F, Wei L, Hubert C, Clauser E, Alhenc-Gelas F, Corvol P. Molecular biology of the angiotensin I converting enzyme: II. Structure-function. Gene polymorphism and clinical implications. J Hypertens 11, 599-604, 1993.

Thorpe SR, Baynes JW. Maillard reaction products in tissue proteins: new products and new perspectives. Amino Acids 25, 275-281, 2003.

Tigerstedt R, Bergman PQ. Niere und Kreislauf1. Skand Arch Physiol 8, 223-271, 1898.

Tipnis SR, Hooper NM, Hyde R, Karran E, Christie G, Turner AJ. A human homolog of angiotensin-converting enzyme. Cloning and functional expression as a captopril-insensitive carboxypeptidase. J Biol Chem, 275, 33238-33243, 2000.

Tonelli M, Muntner P, Lloyd A, Manns BJ, Klarenbach S, Pannu N, James MT, Hemmelgarn BR; Alberta Kidney Disease Network. Risk of coronary events in people with chronic kidney disease compared with those with diabetes: a population-level cohort study. Lancet 380, 807-814, 2012.

van Kats JP, Danser AH, van Meegen JR, Sassen LM, Verdouw PD, Schalekamp MA. Angiotensin production by the heart: a quantitative study in pigs with the use of radiolabeled angiotensin infusions. Circulation 98, 73-81, 1998.

van Kesteren CA, Danser AH, Derkx FH, Dekkers DH, Lamers JM, Saxena PR, Schalekamp MA. Mannose 6-phosphate receptor-mediated internalization and activation of prorenin by cardiac cells. Hypertension 30, 13891396, 1997.

Vignais PV. The superoxide-generating NADPH oxidase: structural aspects and activation mechanism. Cell Mol Life Sci 59, 1428-1459, 2002.

Walters PE, Gaspari TA, Widdop RE. Angiotensin-(1-7) acts as a vasodepressor agent via angiotensin II type 2 receptors in conscious rats. Hypertension 45, 960-966, 2005. 
Watson AM, Li J, Samijono D, Bierhaus A, Thomas MC, Jandeleit-Dahm KA, Cooper ME. Quinapril treatment abolishes diabetes-associated atherosclerosis in RAGE/apolipoprotein E double knockout mice. Atherosclerosis 235, 444-448, 2014.

Weinsaft JW. Effect of ramipril on cardiovascular events in high-risk patients. N Engl J Med 343, 64-66, 2000.

Westermann D, Rutschow S, Jager S, Linderer A, Anker S, Riad A, Unger T, Schultheiss HP, Pauschinger M, Tschope C. Contributions of inflammation and cardiac matrix metalloproteinase activity to cardiac failure in diabetic cardiomyopathy: the role of angiotensin type 1 receptor antagonism. Diabetes 56, 641-646, 2007.

Wu C, Lu H, Cassis LA, Daugherty A. Molecular and pathophysiological features of angiotensinogen: A mini review. N Am J Med Sci (Boston) 4, 183-190, 2011.

Wu L, Iwai M, Li Z, Li JM, Mogi M, Horiuchi M. Nifedipine inhibited angiotensin II-induced monocyte chemoattractant protein 1 expression: involvement of inhibitor of nuclear factor kappa B kinase and nuclear factor kappa B-inducing kinase. J Hypertens 24, 123-130, 2006.

Xiao L, Pimentel DR, Wang J, Singh K, Colucci WS, Sawyer DB. Role of reactive oxygen species and NAD $(\mathrm{P}) \mathrm{H}$ oxidase in alpha(1)-adrenoceptor signaling in adult rat cardiac myocytes. Am J Physiol Cell Physiol 282, C926-C934, 2002.

Zheng J, Wei CC, Hase N, Shi K, Killingsworth CR, Litovsky SH, Powell PC, Kobayashi T, Ferrario CM, Rab A, Aban I, Collawn JF, DellItalia LJ. Chymase mediates injury and mitochondrial damage in cardiomyocytes during acute ischemia/reperfusion in the dog. PLoS One 9, e94732, 2014. 